
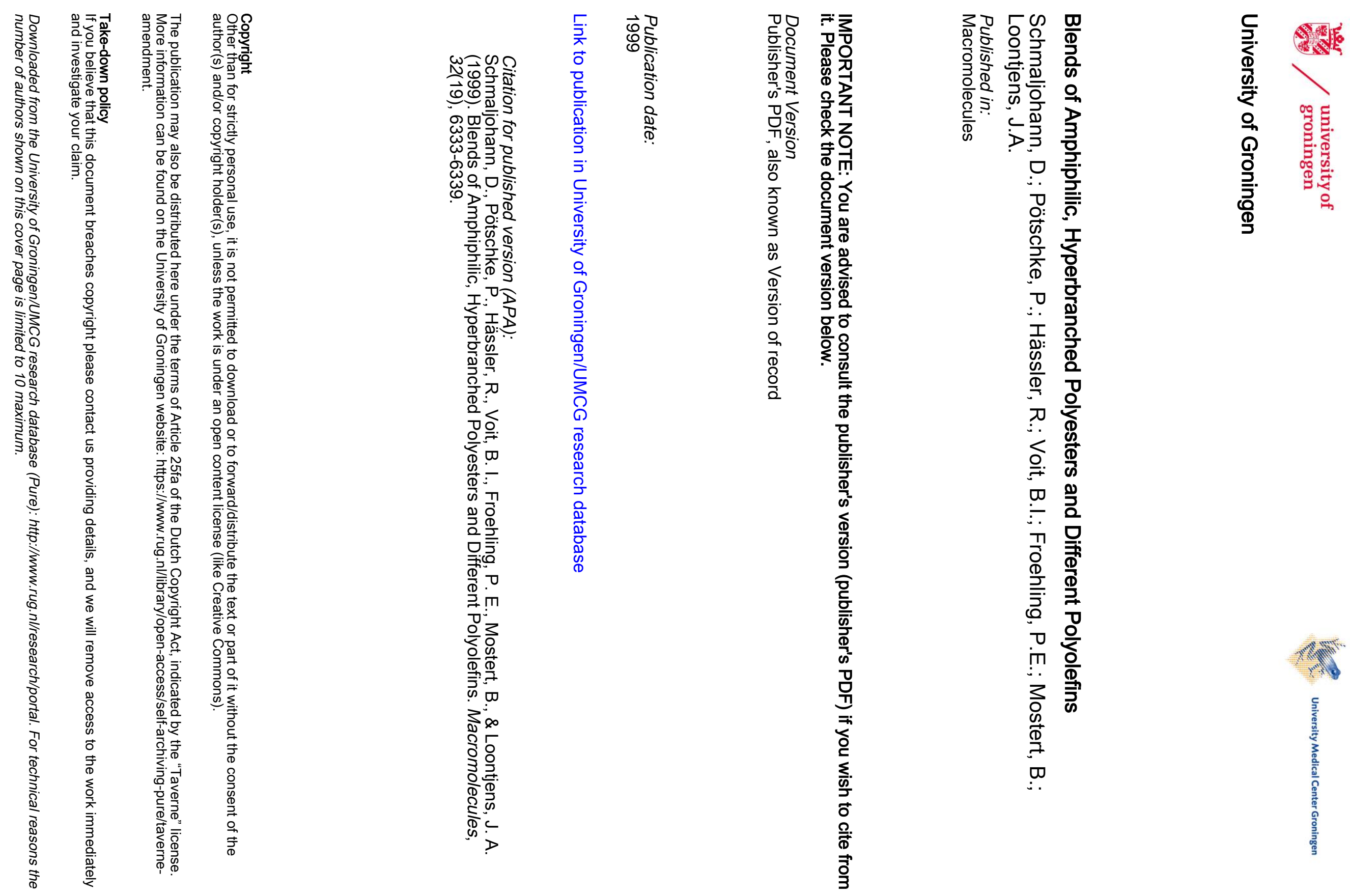

곡

음

$\therefore$ อ

도 옥

क्ष

D

?ִ.

○

๓๐

꿍뭉

田

흘

oิ

응

!1

उ

吕

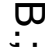

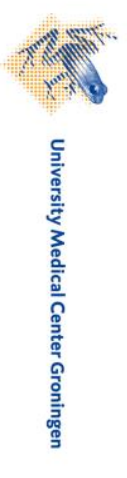




\title{
Blends of Amphiphilic, Hyperbranched Polyesters and Different Polyolefins
}

\author{
D. Schmaljohann, ${ }^{\dagger}$ P. Pötschke, R. Hässler, and B. I. Voit* \\ Institute of Polymer Research, O1069Dresden, Germany
}

P. E. Froehling, B. Mostert, and J. A. Loontjens

DSMResearch, 6160MD Geleen, The Netherlands

Received February 22, 1999, Revised Manuscript Received June 28, 1999

\begin{abstract}
A hyperbranched polyester based on 3,5-dihydroxybenzoic acid was completely modified with dodecanoyl chloride to result in an amphiphilic, globular polymer, which has a polar core and a nonpolar outer sphere with the ability both toincorporate an organic dye and tointeract with a nonpolar matrix. A series of blends were prepared using either polypropylene or polyethylene (HDPE) as the matrix. The content of the polyester as disperse phase was varied between 0.05 and $20 \mathrm{wt} \%$. The blends with polyester contents up to 5\% were prepared for colorization of polyolefins using the polyester as a dye carrier. The blends with higher polyester contents were prepared in order to investigate the influence of the hyperbranched material on the material properties. The blends exhibited a heterogeneous morphology with very small particle sizes even at high polyester concentrations. The melt rheology measurements resulted in a reduced complex viscosity for both polyol efins when the hyperbranched polyester was added. The observed melt viscosity of the $i$-PP blends deviated from the linear mixing rule, whereas the HDPE blends followed it. The use of amphiphilic hyperbranched polyesters as dye carriers allowed a homogeneous distribution of an organic dye in a polyolefin matrix with similar dynamic-mechanical behavior of the blends compared to the case of pure polyolefins. The dyed samples exhibited good stability in extraction experiments.
\end{abstract}

\section{Introduction}

Hyperbranched polymers feature a large number of functional groups, low melt viscosities, and a globular, three-dimensional structure. ${ }^{1,2}$ Due to their globular structure, dendrimers and hyperbranched polymers are discussed as carrier molecules. Dendrimers can be used in medical applications, e.g., as a drug carrier, due to their well-defined structure and molar mass. On the other hand, the nonperfect analogues to the dendrimers, the hyperbranched polymers, can be used in less sensitive fields. Since every hyperbranched polymer based on an $\mathrm{AB}_{2}$ system has $n+1 \mathrm{~B}$ functionalities per molecule (with $n=$ degree of polymerization), a large number of functional groups are accessible for further modification reaction. ${ }^{3-5}$ These functionalities can be used either tochange the polarity or tointroduce special (reactive) groups. Furthermore, the low melt viscosity of hyperbranched polymers offers applications as melt modifiers or blend components.

Dendrimers and hyperbranched polymers have been used as blend material following different aims. Kim et al. ${ }^{6}$ blended hyperbranched polyphenylene with polystyrene. The resulting blends exhibited improved thermal stability and a reduced melt viscosity at high temperatures and high shear rates. Blends of hyperbranched polyesters, ${ }^{7}$ aryl ester dendrimers, ${ }^{8}$ and PAMAM dendrimers ${ }^{9}$ with different linear polymers such as polyesters, ${ }^{7,8}$ polyamides, ${ }^{7}$ polycarbonate, ${ }^{7}$ poly(vinyl chloride), ${ }^{9}$ and poly(vinyl acetate) ${ }^{9}$ have been studied with regard tocompatibility and change in mechanical properties. Khadir et al. ${ }^{10,11}$ prepared an arborescent polystyrene and blended it with linear polystyrene and

\footnotetext{
${ }^{\dagger}$ Present address: Department of Materials Science and Engineering, Cornell University, Ithaca, NY 14853.
}

poly(methyl methacrylate), respectively. The properties of these blends changed with the arm length of the arborescent polymer. As long as the arm length was below the critical length of entanglements, a segregation of the arborescent polymers was observed which was in agreement with theoretical calculations. ${ }^{12}$ The segregation resulted in an extremely low apparent viscosity, and this so-called lubricant effect is of interest when the polymers are applied as melt modifiers. The use of dendritic polymers as carrier molecules in blends has been reported by de Brabander-van den Berg et al. ${ }^{13}$ The carrier function of branched polymers was described for various systems of hyperbranched polymers or dendrimers in different matrices of linear polymers. However, the rheology behavior of dendritic macromolearles ${ }^{14-16}$ and blends ${ }^{10,11}$ with dendritic components has been studied only in very few cases up to now. Hawker and co-worker ${ }^{15}$ found unusual melt rheology behavior for poly(benzyl ether) dendrimers. Poly(amidoamine) (PAMAM) dendrimers in concentrated ethylenediamine solutions exhibited Newtonian flow behavior as studied by Dvornic et al. ${ }^{16}$

The focus of our study was the synthesis of an amphiphilic hyperbranched polyester and the investigation of its ability to blend with different polyolefins. The hyperbranched polyester based on 3,5-dihydroxybenzoic acid was synthesized and modified quantitatively with a dodecanoyl chloride toyield a product with a polar core and a nonpolar outer sphere. ${ }^{5}$ Now, this polymer can act as a carrier of polar organic additives, and the nonpolar fatty acid chain ends should improve the compatibility with polyolefins (Scheme 1).

Possible additives are dyes, fire retardants, UV stabilizers, antioxidants, and thermal stabilizers. At present, the colorization of the polypropylene fibers is 
still an industrial problem. Inorganic pigments as well as polar organic dyes cannot be mixed homogeneously into the matrix without any carrier. ${ }^{13}$

Besides the function as carrier molecules, the effect of a hyperbranched material on the mechanical properties of the linear matrix polymer is also of interest. Therefore, also larger amounts (up to $20 \mathrm{wt} \%$ ) of the hyperbranched polyester were blended with polyolefins, and the melt rheology and dynamic mechanical behavior of the blends have been studied.

\section{Experimental Section}

Synthesis of the Dodecanoyl-Terminated Hyperbranched Polyester P 1-C 12 The synthesis and characterization of P 1-C 12 were carried out as described previously. ${ }^{5}$

Molar mass: $M_{\mathrm{h}}=65000 \mathrm{~g}$ mol, $M_{\mathrm{v}}=142000 \mathrm{~g}$ mol (SEC: Waters 51O, RI detector, columns Waters Ultrastyragel $10^{3} \AA, 10^{4} \AA, 10^{5} \AA$, solvent THF, polystyrene standard).

Incorporation of the Dye "Oracet Blue B". A $5.16 \mathrm{~g}$ sample of P 1-C 12 was dissolved in $80 \mathrm{~mL}$ of toluene and precipitated into a solution of $222 \mathrm{~g}$ of 1 -( $N$-methylamino) 4 ( $N$-phenylamino)anthraquinone (Oracet Blue B, C.I. 61515) in $800 \mathrm{~mL}$ of methanol. The colorized polymer P 1 (dye)-C 12 was filtered off and washed intensively with $3 \mathrm{~L}$ of methanol. UV measurements using a Varian Cary 3 on the dissolved dye containing polymer resulted in a dye content of 425 wt \% (measurement in dioxane, evaluation of the absorption maximum at $610 \mathrm{~nm}$ ).

Blend Preparation. The blend preparation was carried out in a DSM twin-screw miniextruder with a mixing compartment volume of ca. $5 \mathrm{~mL}$.

Two commercial polyolefins were used as matrix polymer: the isotactic polypropylene (i-PP) DSM Stamylan P $19 \mathrm{MN} 10$ $\left(M_{\mathrm{n}}=62400 \mathrm{~g} / \mathrm{mol}, M_{\mathrm{v}}=278000 \mathrm{~g} / \mathrm{mol} ; T_{\mathrm{m}}=170{ }^{\circ} \mathrm{C}\right)$ and the high-density polyethylene (HDPE) DSM Stamylan 6621 $\left(M_{h}\right.$ $=14300 \mathrm{~g}$ mol, $M_{\mathrm{v}}=169000 \mathrm{~g}$ mol, $\left.T_{\mathrm{m}}=139^{\circ} \mathrm{C}\right)$. The molar masses of the two polyolefins were determined by SEC at 135 ${ }^{\circ} \mathrm{C}$ with 1,2,4-trichlorobenzene as solvent using polypropylene and polyethylene standards, respectively. As a second component (disperse phase), the dye containing polyester P1(dye)C 12 and P 1-C 12 (without dye), respectively, were used. The melt transitions and glass temperatures of the blend components and the blends were analyzed by differential scanning calorimetry (Perkin-Elmer DSC7) with a heating rate of 20 K tmin.

The two components (polyolefin and polyester) were premixed as powders and filled intothe extruder. The melt mixing temperature was $200^{\circ} \mathrm{C}$ for $i$-PP blends and $220^{\circ} \mathrm{C}$ for HDPE blends. A controlling device at the extruder allowed a separate adjustment of both the mixing time and the screw speed. Simultaneously, the torque was measured during the complete mixing process. The final mixing time was chosen to be $4 \mathrm{~min}$ for all blends, which was far after the torque had reached a minimum plateau value. The screw speed was set at $240 \mathrm{rpm}$. All blends were cooled rapidly in air after the extrusion process in order to reduce the crystallization of the polyolefins. For comparison, the pure blend components $i$-PP and HDPE were treated in the same way before thermal analysis.

Scanning Electron Microscopy (SEM). The extruded samples were aut with a cryomicrotome device. Then the disperse phase (polyester) was extracted with THF for $24 \mathrm{~h}$ at room temperature. The samples were sputtered with gold and investigated using a LEO $435 \mathrm{VP}$ at $10 \mathrm{kV}$ with a magnification of 1000 and 5000 .

Particle Size Analysis. The particle size analysis was carried out with the program Optimas 5.23. Since the overall particle size was very small, the standard deviation was large due to either the low resolution (1000x magnification) or the low number of counted partides (5000x magnification). Therefore, the accuracy of these results is only one decimal.

DMA Measurements. All samples for the DMA measurements were prepared by compression molding of shredded extrusion strand for $15 \mathrm{~min}$ at a pressure of $1.6 \mathrm{kN} / \mathrm{km}^{2}$. The

\section{Scheme 1}
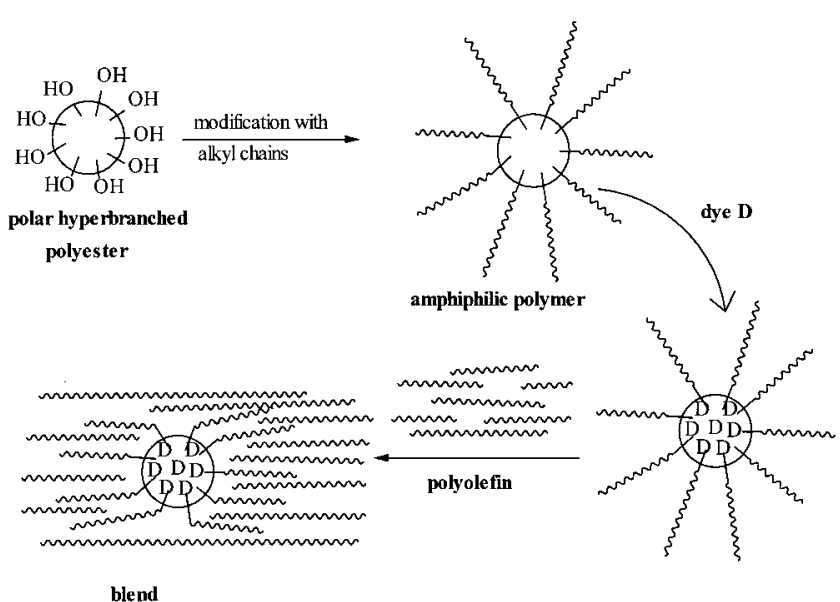

blend

temperature varied according to the different matrix polymers: $200^{\circ} \mathrm{C}$ for $i$-PP blends and $240{ }^{\circ} \mathrm{C}$ for HDPE blends. The measurements were performed using a DuPont Instruments DMA983 with rectangular samples (ca. $8.4 \mathrm{~mm} \times 5.1$ $\mathrm{mm} \times 1.0 \mathrm{~mm})$ in bending mode at resonance at a heating rate of $3 \mathrm{~K}$ trin.

Melt Rheology. The measurements were performed using a Rheometrics ARES with plate-plate geometry in oscillation mode under a nitrogen atmosphere. The plate diameter was $25 \mathrm{~mm}$, and the gap ranged from 1.2 to $1.95 \mathrm{~mm}$. A frequency range between 0.1 and $100 \mathrm{rad} / s$ and a strain within the linear viscoelastic range were used. The samples were investigated as extruded strands. The measurement temperatures were identical to those of the blending experiments $\left(200^{\circ} \mathrm{C}\right.$ for $i$-PP and $220^{\circ} \mathrm{C}$ for HDPE).

Extraction Experiments. The extraction experiments were carried out on the dye-containing blends with water, methand, THF, and an aqueous sodium dodecyl sulfate (SDS) solution $(5.5 \mathrm{mg} / \mathrm{mL})$. Two different temperatures were applied: $25^{\circ} \mathrm{C}$ and the boiling point of the solvent. Extraction experiments with pure solvents at the boiling point were carried out in a Soxhlet apparatus and all other experiments in a round-bottom flask. Duration of the extraction was 5 days (boiling solvent) and 2 months (room temperature), respectively.

\section{Results and Discussion}

The highly activated monomer 3,5-bis(trimethylsiloxy)benzoyl chloride was used for the synthesis of the hyperbranched polyester. ${ }^{17-19}$ After hydrolysis of the trimethylsiloxy groups a polar polymer with hydroxy functionalities was obtained $(\mathrm{P} 1-\mathrm{OH})$. All hydroxy functions could be converted into the corresponding dodecanoates by reaction with dodecanoyl chloride (Scheme 2). ${ }^{5}$

The resulting polymer P 1-C 12 exhibits two thermal transition temperatures $\left(-52\right.$ and $\left.+48^{\circ} \mathrm{C}\right)$ as determined by DSC and DMA. ${ }^{5}$ In a detailed analysis of several hyperbranched polyesters modified with alkyl chains of different chain length, the transition at higher temperature $\left(+48{ }^{\circ} \mathrm{C}\right)$ of $\mathrm{P} 1-\mathrm{C} 12$ could be assigned dearly to the glass transition of the modified polyester whereas the transition at the lower temperature is located even below the temperature for the melting of the side chains when crystallized (between -30and - 1 ${ }^{\circ} \mathrm{C}$ for $\mathrm{C} 14$ to $\mathrm{C} 18^{\circ}$ ). Therefore, a phase separation in alkyl-rich and ester-rich domains is assumed for $\mathrm{P}$ 1$\mathrm{C} 12$ In contrast to experiences with the very brittle starting polymer $\mathrm{P} 1-\mathrm{OH}$, we were able to obtain freestanding films from the alkyl-modified polyester P 1-C 12 by compression molding. In hexane, milky suspensions 


\section{Scheme 2}
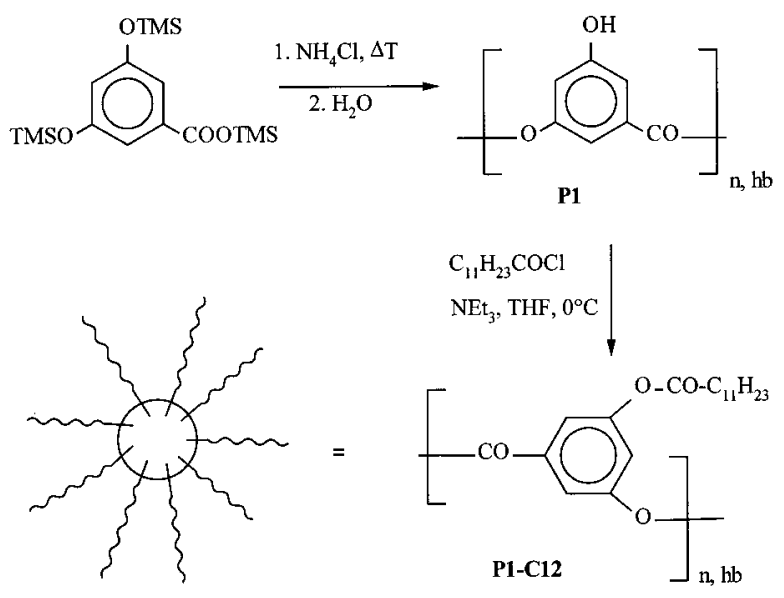

(hb indicates that the polymer structure is hyperbranched)

Table 1. Composition and Final Torque of the Polypropylene/Polyester Blends

\begin{tabular}{|c|c|c|c|c|c|}
\hline $\begin{array}{l}\text { blend } \\
\text { no. }\end{array}$ & $\begin{array}{l}i \text {-PP } \\
\text { (wt \%) }\end{array}$ & $\begin{array}{c}\text { P 1-C } 12 \\
\text { (wt \%) }\end{array}$ & P 1(dye)-C 12 (wt \%) & $\begin{array}{c}\text { dye } \\
\text { (wt \%) }\end{array}$ & $\begin{array}{l}\text { torque } \\
(\mathrm{N} \mathrm{m})\end{array}$ \\
\hline & 100 & & & & 1025 \\
\hline 1 & 99.77 & & & 0.23 & 1050 \\
\hline 2 & 99.949 & & 0.051 (0.002 wt \% dye) & & 925 \\
\hline 3 & 99.89 & & 0. 11 (0.005 wt \% dye) & & 925 \\
\hline 4 & 99.66 & & 0.34 (0.014 wt \% dye) & & 875 \\
\hline 5 & 99.46 & & 0.54 (0.023wt \% dye) & & 1000 \\
\hline 6 & 9490 & & 5. 10 (0.22 wt \% dye) & & 900 \\
\hline 7 & 90.0 & 10.0 & & & 55 \\
\hline 8 & 85.0 & 15.0 & & & 42 \\
\hline \multirow[t]{2}{*}{9} & 80.0 & 20.0 & & & 350 \\
\hline & & 100 & & & \\
\hline
\end{tabular}

of the modified polyester were obtained, indicating its amphiphilic character. With these results, we expected a certain compatibility of the modified hyperbranched polyester with polyolefins, but also some ability to capture polar substances in the polar polyester "core" stabilized by the alkyl chains. An organic dye was taken as a representative for any polar additive.

The inclusion of the dye into the polar polyester core was carried out by precipitation of a polyester solution into a solution of the dye in methanol. An intensive washing procedure was needed to remove dye attached to the outer sphere of P 1-C 12 and not fixed in the core.
This procedure was very efficient, and a relatively high amount of $4.25 \mathrm{wt} \%$ dye (determined by UV measurements) could be incorporated into the hyperbranched polyester (P 1(dye)-C 12).

The blends were prepared in a twin-screw miniextruder at $200{ }^{\circ} \mathrm{C}(i-\mathrm{PP})$ and $220{ }^{\circ} \mathrm{C}(\mathrm{HDPE})$ by first premixing the powders of the components (see Experimental Section). The experiments will be classified in isotactic polypropylene (i-PP) blends and high-density polyethylene (HDPE) blends according to the matrix polymer. Since both classes exhibit different properties, they will be discussed separately.

i-PP Blends. Composition of the Blends. The i-PP blends were prepared in a concentration range of $0.05-$ $20 \%$ polyester (Table 1 ).

Between 0.05 and $5.10 \%$ of the dye-containing polyester P 1(dye)-C 12 was used. For larger contents P 1-C 12 (without dye) was used. For comparison, the dye (without polyester) was mixed with polypropylene, too. In addition, the twostarting polymers, $i$-PP and the hyperbranched polyester P 1-C 12 were extruded separately.

Morphology Investigations. The blends were first investigated by light microscopy. On this scale, all $i$-PP blends exhibited a homogeneaus distribution of the polyester and the dye in the matrix. It is important to note that this homogeneous distribution was achieved by rapid cooling of the samples. When the blends cooled slowly in annealing experiments, the polypropylene showed an enhanced crystallization, which caused a stronger phase separation. The polyester as well as the dye was driven out of the $i$-PP crystallites. This can be observed by switching between the normal light microscope mode and crossed polarizers, which visualizes the $i$-PP crystallites. Nevertheless, visually the colorization still seemed to be homogeneous.

The influence of the hyperbranched polyester was investigated by comparison of two samples with the same content of dye: one without polyester (blend 1) and one with polyester (blend 6, Figure 1). Blend $\mathbf{1}$ exhibits single dye crystals whereas blend $\mathbf{6}$ shows a homogeneous distribution of the dye in the matrix. Thus, the hyperbranched polyester acts as a dye carrier and therefore allows a much better distribution of the dye in the matrix polymer.

Scanning electron microscopy (SEM) allows a more detailed morphology investigation. The extruded samples
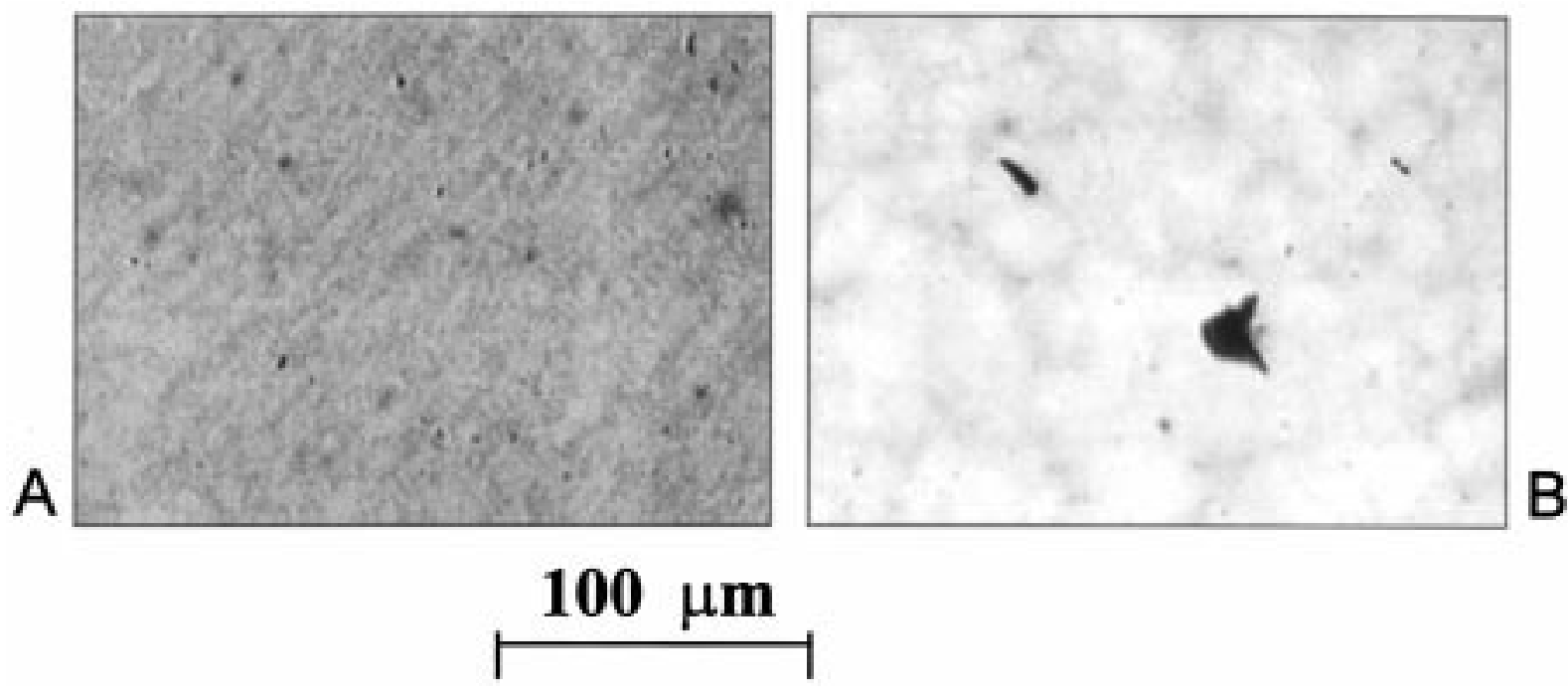

Figure 1. Light microscopy of (A) blend 6 and (B) blend 1 (310-fold magnification). 


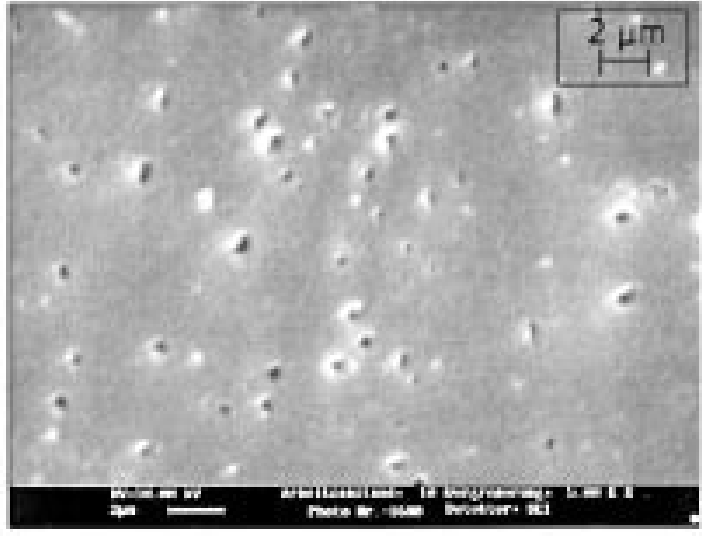

a

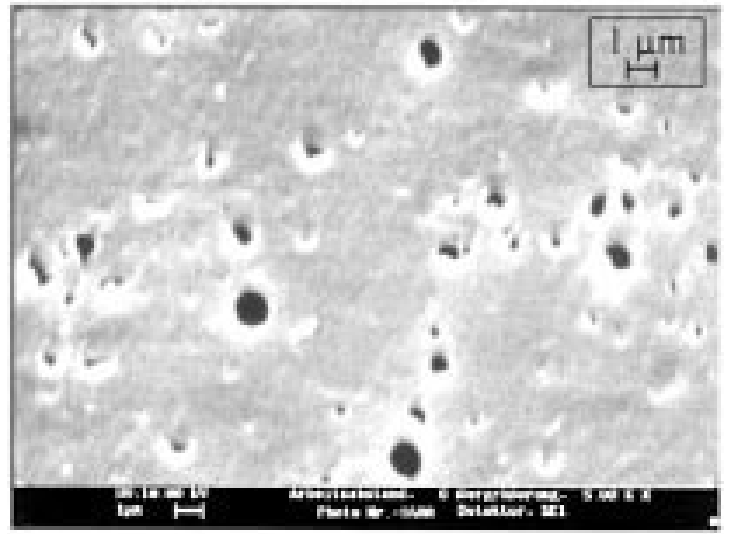

b

Figure 2 Scanning electron microscopy of (a, top) blend $\mathbf{6}$ and (b, bottom) blend 7 (10 kV, cryoaut, disperse phase extracted with THF, 5000-fold magnification).

were cut using a cryomicrotome. The polyester as a disperse phase was extracted with THF in order to enhance the contrast between both phases. The SEM micrographs showed that the blends are heterogeneous on the submicrometer scale (Figure 2). But even at high polyester concentrations (10\% P 1-C 12 , blend 7 ) the particle size is small. Particle size analysis resulted in a medium particle size of 0.3-0.4 $\mu \mathrm{m}$ for blend $6(5 \%$ $\mathrm{P} 1$ (dye)-C 12) and 0.4-0.5 $\mu \mathrm{m}$ for blend 7 (10\% P 1-C 12).

Although the blends are heterogeneous, the small particle sizes indicate a rather good compatibility between matrix and disperse phase, as it was shown by the light microscope investigations.

The preliminary experiments allow the conclusion that the modification with alkyl chains as well as the sample preparation has a fundamental influence on the quality of the products. The alkyl modification of the hyperbranched polyester is essential to overcome repulsion of the two polymers with large differences in polarity. Mixing under high shear rate favors the formation of small particles and rapid cooling stabilizes the morphology. Blend preparation by compression molding without any shearing resulted in large phase separation. As expected, the particle size increases with higher content of polyester, but only slightly.

Rheology. During the mixing process, the torque decreased to a final plateau value due to the ongoing melting of the samples. The final values of the torque (Table 1) show a strong decrease with increasing amount of polyester. Since the hyperbranched polyester

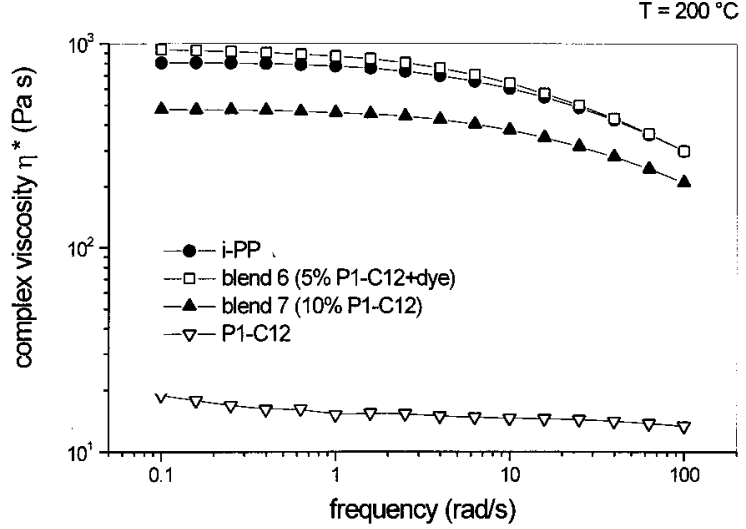

Figure 3. Melt rheology: complex viscosities $\eta^{*}$ of $i$-PP, P 1$\mathrm{C} 12$, and blends 6 and $\mathbf{7}\left(T=200^{\circ} \mathrm{C}\right.$, frequency sweep O. 1$100 \mathrm{rad} / \mathrm{s})$.

itself has a very low torque of $75 \mathrm{~N}$ m at $200{ }^{\circ} \mathrm{C}$, the trend can be expected, but the reduction of the torque is much stronger as expected from the added amounts. Even the lowest polyester concentrations (0.05\% P 1(dye)-C 12, blend 2) yield a significant lower torque. This effect can be attributed to either a lubricant effect of the polyester component (caused by the mixing process and segregation of the polyester to the extruder walls) or an extraordinary property of the polyester as melt modifier. We performed melt rheology measurements toinvestigate which effect is responsible for this extreme decrease in torque. In rheological measurements segregation to the "walls" cannot occur, and therefore the lubricant effect can be mainly excluded.

The measurements were carried out in a frequency sweep at the extrusion temperature $\left(200{ }^{\circ} \mathrm{C}\right)$. The complex viscosity $\eta^{*}$ was obtained, which can be separated into the storage modulus $G$ and the loss modulus $G^{\prime}$. The complex viscosity of the two starting polymers $i$-PP and P $1-\mathrm{C} 12$ at $200^{\circ} \mathrm{C}$ (Figure 3) differ extremely as it was expected from the torque measurements. The zero-shear viscosity (viscosity, extrapolated to a frequency O) is $800 \mathrm{~Pa}$ s for $i$-PP and only $19 \mathrm{~Pa}$ s for $\mathrm{P} 1$ C 12 The hyperbranched polymer has a low viscosity due to its globular structure, the absence of entanglements, and the loss of polar interaction due to the modification with alkyl chains. Furthermore, the viscosity was measured approximately $150 \mathrm{~K}$ above the $T_{\mathrm{g}}$ of $\mathrm{P} 1-\mathrm{C} 12$ and only $30 \mathrm{~K}$ above the melting temperature of $i$-PP. At $110^{\circ} \mathrm{C}\left(60 \mathrm{~K}\right.$ above $\left.T_{\mathrm{g}}\right) \mathrm{P} 1-\mathrm{C} 12$ exhibits a comparable high zero-shear viscosity of about 2800 Pa s. ${ }^{5}$

The blend 7 (10\% P 1-C 12, Figure 3) shows a decrease in the viscosity which exceeds significantly the additive effect calculated by the mixing rule:

$$
\eta^{*}(\mathbf{7})<0.9 \eta^{*}(i-\mathrm{PP})+0.1 \eta^{*}(\mathrm{P} 1-\mathrm{C} 12)
$$

The zero-shear viscosity of blend 7 has a value of 480 $\mathrm{Pa} \mathrm{s}$, which is deviating from the mixing rule by the factor of 0.66. And the torque measurement on this sample is deviating by the factor 0.59 from the mixing rule. From these results one can conclude that the reduction of the torque is not due to a lubricant effect. The hyperbranched polyester P 1-C 12 seems to cause a decrease in the viscosity of the polypropylene matrix.

The situation is different for the dye-containing blends: the complex viscosity of blend 6 (5\% P 1(dye)$\mathrm{C} 12$ zero-shear viscosity: $930 \mathrm{~Pa}$ s) exceeds the value 


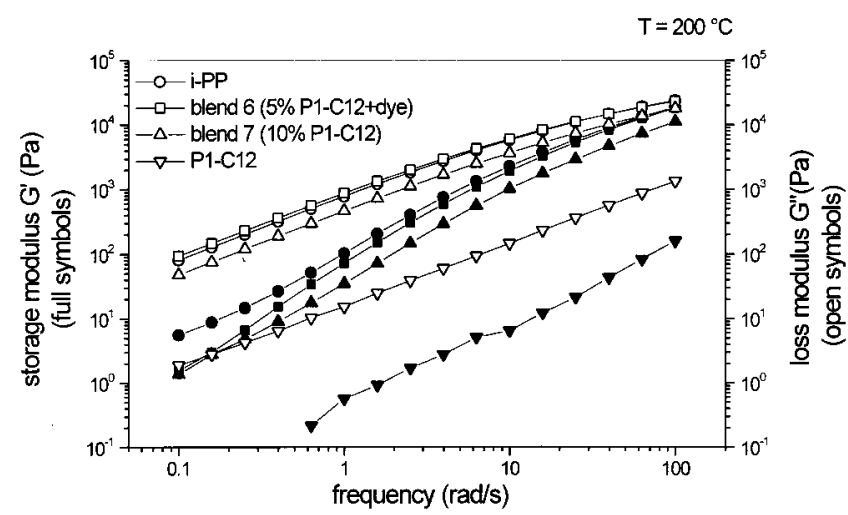

Figure 4. Melt rheology: storage modulus $G$ (full symbols) and loss modulus $G^{\prime}$ (open symbols) of $i$-PP, $\mathrm{P} 1-\mathrm{C} 12$, and blends 6 and $7\left(T=200^{\circ} \mathrm{C}\right.$, frequency sweep O. $\left.1-100 \mathrm{rad} / s\right)$.

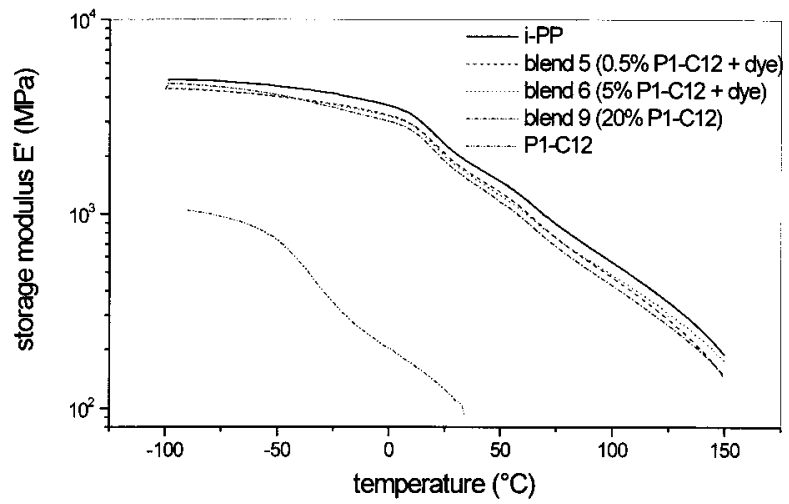

Figure 5. Dynamic-mechanical analysis: storage modulus $E^{\prime}$ vs temperature of $i \mathrm{PP}, \mathrm{P} 1-\mathrm{C} 12$ and blends $5, \mathbf{6}$, and 9 (3 $\mathrm{K}$ tmin, resonance mode)

of the $i$-PP. This increase has to be attributed to a conformational change of the hyperbranched polyester due to the incorporated dye.

Plotting the storage $\left(G^{\prime}\right)$ and the loss modulus $\left(G^{\prime}\right)$ against the frequency, one can see that the curve of the loss modulus is located always above that of the storage modulus (Figure 4). The viscous part of the complex melt viscosity is represented by $G^{\prime \prime}$ whereas the elastic part is described by $G$. Thus, these blends show mainly a viscous behavior at $200{ }^{\circ} \mathrm{C}$ rather than an elastic behavior. This agrees with the observation that all $i$-PP blends were extremely fluid when they were taken out of the extruder.

Dynamic-Mechanical Analysis and Differential Scanning Calorimetry. The film obtained by compression molding from P 1-C 12 is very weak, breaks easily, and exhibits no significant tensile strength. These poor mechanical properties of the hyperbranched polymer result in much lower storage modulus $E^{\prime}$ as followed by DMA measurement compared to the case of $i$-PP (Figure 5). The reasons for this are the lack of crystallinity and the absence of entanglements in hyperbranched polyesters. Only weak hydrophobic interactions of the alkyl chains contribute to the mechanical stability of P 1-C 12

Despite this fact, the DMA measurements of blends 5 (0.5\% P 1(dye)-C 12), 6 (5\% P 1(dye)-C 12), and even 9 (20\% P 1-C 12, Figure 5) exhibit E modulus traces close to that of pure $i$-PP, which shows that the $E$ modulus is not influenced strongly by the polyester content. For the highest polyester concentration (20\%, blend 9) a small loss in $E^{\prime}$ at approximately $-35^{\circ} \mathrm{C}$ was observed, which corresponds to the low-temperature thermal transition of the starting polyester $\mathrm{P} 1-\mathrm{C} 12^{5}$
Evaluation of the $E^{\prime \prime}$ curves exhibited that the relaxation peak temperature for the pure $i$-PP at $19^{\circ} \mathrm{C}$ is not changed even in the blend with $20 \% \mathrm{P} 1-\mathrm{C} 12$, indicating phase separation. We observed for pure $\mathrm{P} 1$ $\mathrm{C} 12$ a low-temperature transition at $-47^{\circ} \mathrm{C}\left(E^{\prime \prime}\right)$ in the DMA measurements. This peak becomes visible in the blends at a polyester content of $20 \%$ and is shifted to $-33^{\circ} \mathrm{C}\left(E^{\prime \prime}\right)$.

DSC measurement revealed the glass transition of the hyperbranched polyester already at low content (even below $5 \%$ ) in the range of +48 to $+56{ }^{\circ} \mathrm{C}$, and the melting transition of the polypropylene was not influenced, staying at $170-172{ }^{\circ} \mathrm{C}$ which is clearly an indication for a phase-separated system. The melting enthalpy of the $i$-PP in the blend decreased with increasing polyester content from $100 \mathrm{~J} / g(i-\mathrm{PP})$ to 75 $\mathrm{J} / \mathrm{g}$ (i-PP $/ 2 \mathrm{O} \% \mathrm{P} 1-\mathrm{C} 12)$ with an unproportional jump from 100 to $87 \mathrm{~J} / \mathrm{g}$ for very low polyester concentrations (0.05\% P 1-C 12). It was found that the addition of any second component even at very low concentrations decreases the degree of crystallinity of the polyolefins.

Resistance of the Dye-Containing Blends against Solvents. As shown above, the use of the amphiphilic hyperbranched polyester as a dye carrier allowed a homogeneous colorization of $i$-PP. Since polypropylene is a fiber material, the homogeneous and permanent colorization with a minimum amount of dye is important. We tested the color stability of these blends in extraction experiments with different solvents (methand, THF, water) and also with a soap solution. We chose methand because it dissolves the dye but not the hyperbranched polyester or the polypropylene. THF dissolves the dye and the polyester but not the polyolefin. Water and a sodium dodecyl sulfate (SDS) solution were tested because these solvents are important for the intended application.

With water and methanol no dye was extracted even at the boiling point of the solvent, whereas THF extracted the hyperbranched polyester and the dye at room temperature easily. The reason for the latter is the high degree of swelling of polypropylene in THF (14.5 wt \%) and the solubility of the polyester in this solvent. The SDS solution shows no effect at room temperature, but at $100^{\circ} \mathrm{C}$ the dye is extracted from the matrix. Both the SDS solution and the hyperbranched polyester show surfactant properties, and at $100^{\circ} \mathrm{C}$ the polyester part is already in the viscous state and therefore exhibits high mobility. In summary, the extraction stability of the dye is not excellent, but it is sufficiently high for the first experiments.

HDPE Blends. Composition of the Blends. The HDPE blends were also prepared in a concentration range of $0.05-20 \%$ polyester together with tworeference samples (HDPE and HDPE + dye) (Table 2).

Morphology Investigations. The morphology investigations exhibited similar results compared to the case of $i$-PP blends. Again, a homogeneous distribution for the polyethylene polyester blends was found by using light microscopy, whereas SEM verifies that the blends are heterogeneous. The polyethylene chain structure is doser to that of the dodecanoyl residues of P 1-C 12 compared to polypropylene. This seems to result in a better compatibility. At least, we observed smaller polyester particles in the HDPE blends compared to the $i$-PP blends: mean number-average particle diameter of $\mathrm{O} .1-0.2 \mu \mathrm{m}$ for blend 16 (5\% P $1-\mathrm{C} 12)$ and $0.4 \mu \mathrm{m}$ for blend 17 (10\% P 1-C 12). This is even more relevant since 
Table 2 Composition and Final Torque of the Polyethylene/Polyester Blends

\begin{tabular}{|c|c|c|c|c|c|}
\hline $\begin{array}{c}\text { blend } \\
\text { no. }\end{array}$ & $\begin{array}{l}\text { HDPE } \\
\text { (wt \%) }\end{array}$ & $\begin{array}{c}\text { P 1-C } 12 \\
\text { (wt \%) }\end{array}$ & P 1(dye)-C 12 (wt \%) & $\begin{array}{c}\text { dye } \\
\text { (wt \%) }\end{array}$ & $\begin{array}{c}\text { torque } \\
(\mathrm{N} \mathrm{m})\end{array}$ \\
\hline & 100 & & & & 2800 \\
\hline 10 & 99.76 & & & 0.24 & 2850 \\
\hline 11 & 99.949 & & 0.051 (0.002 wt \% dye) & & 2750 \\
\hline 12 & 99.89 & & O. 11 (0.005wt \% dye) & & 2700 \\
\hline 13 & 99.48 & & 0.52 (0.022 wt \% dye) & & 2675 \\
\hline 14 & 9894 & & 1.06 (0.045 wt \% dye) & & 2650 \\
\hline 15 & 94.96 & & 5.04 (0.21 wt \% dye) & & 2575 \\
\hline 16 & 9495 & 5.05 & & & 2550 \\
\hline 17 & 89.98 & 10.02 & & & 2025 \\
\hline 18 & 85.01 & 14.99 & & & 1825 \\
\hline 19 & 79.97 & 20.03 & & & 1500 \\
\hline
\end{tabular}

the differences in melt viscosity between the two components are more pronounced compared to the case of $i$-PP blends (see below), and therefore good melt mixing is more difficult.

Rheology. Again, the torque measured during blend preparation was extremely decreased by the addition of the hyperbranched polyester to HDPE (Table 2). However, mixing of HDPE with pure dye (without polyester, blend 10) raised the torque compared to that of pure HDPE, and also the comparison of blend 15 (5\% P 1(dye)-C 12) and $\mathbf{1 6}$ (5\% P 1-C 12) showed that the dye incorporated in the polyester effects a slightly higher torque.

Rheological measurements exhibited different results compared to the case of $i$-PP blends. The complex viscosity $\eta^{*}$ of the pure HDPE and its blends did not level out at low frequencies to a plateau value (at the measured temperature and the frequency range, Figure 6). Therefore, the determination of a zero-shear viscosity and direct comparison of the values were not possible. However, it can be observed that the differences in melt viscosities between the starting materials HDPE ( $\eta^{*}(\mathrm{O} .1$ $\left.\operatorname{rad} s)=18000 \mathrm{~Pa} s, T=220^{\circ} \mathrm{C}\right)$ and $\mathrm{P} 1-\mathrm{C} 12\left(\eta^{*}(\mathrm{O} .1\right.$ $\left.\operatorname{rad} s)=9 \mathrm{~Pa} s, 220^{\circ} \mathrm{C}\right)$ are even more dramatic than those in the $i$-PP blends.

The pure HDPE and the blend 16 (5\% P 1-C 12) have nearly identical viscosity curves, whereas slight deviations can be observed for higher polyester contents. The detailed analysis showed that the melt viscosity of blend 17 (10\% P 1-C 12) follows exactly the linear mixing rule:

$$
\eta^{*}(\mathbf{1 7})=0.9 \eta^{*}(\mathrm{HDPE})+\mathrm{O} .1 \eta^{*}(\mathrm{P} 1-\mathrm{C} 12)
$$

In this case, the observed strong reduction in the torque has to be attributed to a lubricant effect and not to a reduction of the melt viscosity of the matrix polymer.

Again, the behavior of the dye-containing blend 15 deviates from these results. The slope is smoother, and at low frequencies the complex viscosity is much lower compared to those of the other blends. Since the lowfrequency region provides information on molecular motion and changes in the structure, we can conclude that also for the HDPE blends the incorporation of the dye into the hyperbranched polyester causes a structural change.

Plotting the storage modulus $G$ versus the loss modulus $G^{\prime \prime}$, one can see the similarity of the results for pure HDPE and for blends 16 and 17 (Figure 7).

The intersection $\left(G^{\prime}=G^{\prime}\right)$ determines the transition from more viscous behavior $\left(G<G^{\prime}\right)$ to more elastic behavior $\left(G>G^{\prime}\right)$. The crossover points for these samples are quite close to each other (HDPE, 0.29 rad/ s; 16, $0.24 \mathrm{rad} / s ; 17,0.44 \mathrm{rad} / s)$. On the other hand, the

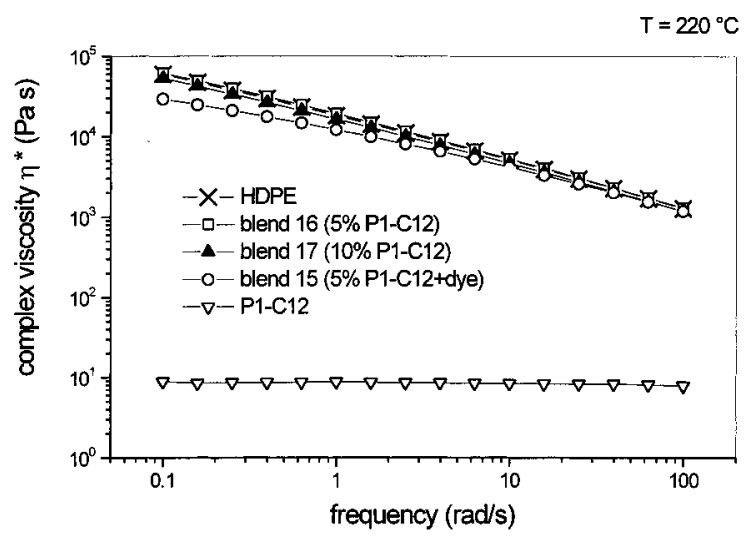

Figure 6. Melt rheology: complex viscosities $\eta^{*}$ of $\mathrm{HDPE}$, $\mathrm{P} 1-\mathrm{C} 12$, and blends 15,16 , and $17\left(T=22 \mathrm{O}^{\circ} \mathrm{C}\right.$, frequency sweep O. 1- $100 \mathrm{rad} / \mathrm{s})$.

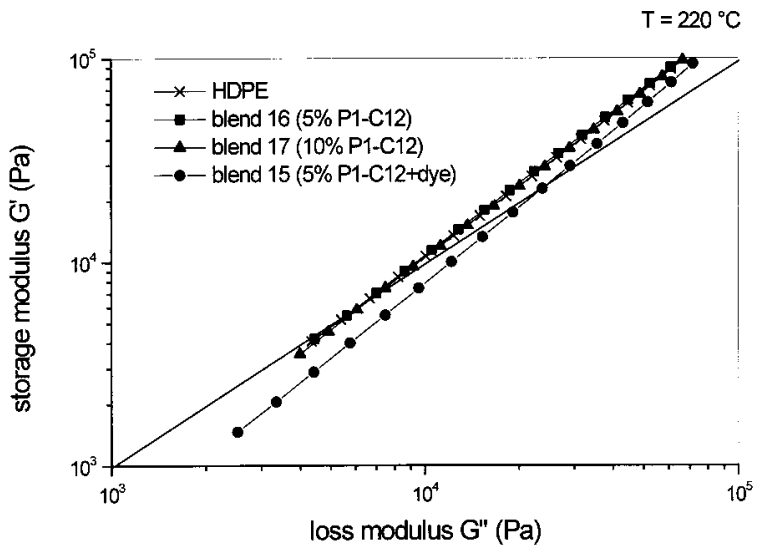

Figure 7. Storage modulus $G$ vs loss modulus $G^{\prime}$ of HDPE and blends 15, 16, and 17 (from melt rheology, $T=220^{\circ} \mathrm{C}$, frequency sweep $0.1-100 \mathrm{rad} /$ ).

dye-containing blend 15 exhibits a more viscous behavior with a crossover-point at $8.1 \mathrm{rad} / \mathrm{s}$. As discussed above, in contrast to these results, the $i$-PP blends exhibited a predominant viscous behavior, and no crossover point was observed.

Dynamic-Mechanical Analysis and Differential Scanning Calorimetry. The dynamic-mechanical studies on the HDPE $\gg 1-C 12$ blends allow the same conclusion than for the PP P 1-C 12 blends: The mechanical properties of the blends are mainly determined by the matrix polymer. The plots of the storage modulus $E^{\prime}$ versus temperature reveal for all blends curves in the same range of pure HDPE with the traces for blends 14 and 15 even slightly above that of HDPE. As expected, the polyester low-temperature transition at about $-35^{\circ} \mathrm{C}$ is only observable as a small decrease in $E^{\prime}$ at a high polyester concentration (blend 19).

The evaluation of the $E^{\prime \prime}$ curves showed that the thermal relaxation peak of the $\mathrm{HDPE}$ at $60^{\circ} \mathrm{C}$ is slightly reduced to $53{ }^{\circ} \mathrm{C}$ in the blend 19 (20\% P 1-C 12). This indicates a certain compatibility between both blends. The low-temperature transition of $\mathrm{P} 1-\mathrm{C} 12$ is shifted from -47 to $-35^{\circ} \mathrm{C}$, similar to the $i$-PP blends.

In contrast to the results on $i$-PP, DSC measurements revealed the glass transition of the polyester in the HDPE blends only at polyester concentrations of 15 and $20 \%$ (transition between 54 and $68^{\circ} \mathrm{C}$ ) but, again, no remarkable shift in the melting transition of the polyethylene (between 139 and $142{ }^{\circ} \mathrm{C}$ ) over all blend compositions. However, the melting enthalpy decreased similar to the $i$-PP blends from $176 \mathrm{~J} / g$ (HDPE) to 128 
$\mathrm{J} / \mathrm{g}$ (HDPE $20 \%$ P 1-C 12) with a strong drop to $157 \mathrm{~J} / \mathrm{g}$ already for very low polyester concentrations $(0.05 \% \mathrm{P} 1-$ $C 12)$. Then, the melting enthalpy decreased slower to $152 \mathrm{~J} / g$ (5\% P 1-C 12), $146 \mathrm{~J} \mathrm{~kg}$ (10\% P 1-C 12), and finally to $128 \mathrm{~J} / g(20 \% \mathrm{P} 1-\mathrm{C} 12)$.

Resistance of the Dye-Containing Blends against Solvents. The dye-containing HDPE blended show analogous results compared to the $i$-PP blends: color resistance toward methand and water, solubility of the disperse phase in THF, and also decolorization in SDS solution at elevated temperatures.

\section{Conclusions}

The effect of modified hyperbranched polyesters in blends with polyolefins was studied. The $\mathrm{OH}$ end groups of the aromatic hyperbranched polyester were reacted to $100 \%$ with dodecanoyl chloride to achieve a good compatibility with the polyolefin matrix polymer. As expected, the HDPE blends showed a better compatibility compared to the $i$-PP blends due to the structural similarity between the polyethylene backbone and the C 12 alkyl chains. But for both polyolefins very small particles $(<0.5 \mu \mathrm{m})$ of the dispersed polyester phase were observed which proves the validity of the concept.

The amphiphilic hyperbranched polyester can act as a carrier for polar organic additives. We proved this by incorporation of the dye Oracet Blue B in the polyester and subsequent melt mixing with polyolefins. The dye was distributed homogeneously within the scale of the light microscope using the polyester as carrier whereas large dye crystals could be observed when the polyolefin was mixed directly with the dye. Extraction experiments also showed that the color stability was excellent in water, methanol, and cold soap solution, but THF and hot sodium dodecyl sulfate solution resulted in decolorization.

The dynamic-mechanical properties of the polyolefins were mainly preserved after blending with the polyester, even at a high polyester content of $10 \%$. The rheological properties of the blends depended on the type of polyolefin and on the dye. The hyperbranched polyester has a very low melt viscosity at the processing temperature, but we observed for all blends a even stronger reduction of the torque during the mixing procedure as expected from the added amount of polyester. The measured complex melt viscosity of polypropylene P 1-C 12 blends was also lower than predicted by the additive effect of the linear mixing rule. On the other hand, the melt viscosity data of polyethylene blends fulfilled the mixing rule. In this case, the strong decrease in the torque during blend preparation must be explained as a lubricant effect. Using $5 \mathrm{wt} \%$ of the dye-loaded P 1 (dye)$\mathrm{C} 12$ the $i$-PP blend showed an increase in the complex viscosity whereas the HDPE blend exhibited a significant decrease in the complex viscosity (compared to the corresponding polyolefin P 1-C 12 blend without dye). Since both effects are dominant in the low-frequency region, this deviation may be assigned to a change in the structure of the hyperbranched particles as dispersed phase by the dye incorporation.
Our procedure to incorporate the additive into the hyperbranched polyester has the advantages that it can be applied to any kind and also mixtures of polar additives. Since the additive is not covalently bonded but physically included, the carrier system can be prepared by simple coprecipitation of the components. Furthermore, different matrix polymers can be used when the polarity of the outer sphere of the polyester is adjusted to the matrix by a modification reaction.

Beside the function as a carrier for additives, the alkyl-modified hyperbranched polyester can also be used as processing aid because of the observed strong reduction of the mixing torque. For polyolefins, in addition to a good distribution of the additive with nearly no change in the dynamic mechanical behavior, lower energy input will be necessary during processing due to the decreased torque.

Acknowledgment. This research was sponsored by the DSM Research, Geleen, which is gratefully acknowledged. The authors thank A. Gehring for SEM measurements and particle size analysis.

\section{References and Notes}

(1) Fréchet, J. M. J.; Hawker, C. J. Synthesis and properties of Dendrimers and Hyperbranched Pdymers. In Comprehensive Polymer Science, Aggarwal, S. L., Russo, S., Eds.; Pergamon Press: Oxford, 1996, 2nd Suppl., p 71 and references therein.

(2) Voit, B. I. Acta Polym. 1995, 46 87-99.

(3) Wooley, K. L.; Hawker, C. J.; Lee, R.; Fréchet, J. M. J. Polym. J. 1994, 26 187-197.

(4) Malmström, E.; Johansson, M.; Hult, A. Macromol. Chem. Phys. 1996, 197, 3199-3207.

(5) Schmaljohann, D.; Loontjens, J. A.; Häusler, L.; Pötschke, P.; Voit, B. I. Macromol. Chem. Phys., in press.

(6) Kim, Y. H.; Webster, O. W. Macromolecules 199225 55615572.

(7) Massa, D. J.; Shriner, K. A.; Turner, S. R.; Voit, B. I. Macromolecules 1995, 28 3214-3220.

(8) Carr, P. L.; Davies, G. R.; Feast, W. J.; Stainton, N. M Polymer 1996, 37, 2395-2401.

(9) Nunez, C. M.; Andrady, A. L.; Guo, R. K.; Baskir, J. N.; Morgan, D. R. J. Polym. Sci. A, Polym. Chem. 1998, 36 2111.

(10) Khadir, A.; Gauthier, M. Polym. Mater. Sci. Eng. 1997, 77, $174-175$.

(11) Khadir, A.; Gauthier, M. Ann. Technol. Cont-Soc. Plast. Eng. 1997, 55,3732

(12) Yethiraj, A. Phys. Rev. Lett. 1995, 74 2018-2021.

(13) de Brabander-van den Berg, E. M. M; Froehling, P. E.; Stevelmans, S.; van Hest, J. C. M. Int. Pat. WO97/1998 assigned to DSM Research, 1996; Chem. Abstr. 1997, 127, 82286.

(14) Hempenius, M. A.; Zoetelief, W. F.; Gauthier, M.; Möller, M. Macromolecules 1998, 31,2299.

(15) Hawker, C. J.; Farrington, P. J.; Mackay, M. E.; Wooley, K. L.; Fréchet, J. M. J. J. Am. Chem. Soc. 1995, 117, 4409

(16) Uppuluri, S.; Keinath, S. E.; Tomalia, D. A.; Dvornic, P. R. Macromolecules 1998, 31, 4498

(17) Kricheldorf, H. R.; Zang, Q.-Z.; Schwarz, G. Polymer 1982 23 1821- 1829 .

(18) Hawker, C. J.; Lee, R.; Fréchet, J. M. J. J. Am. Chem. Soc. 1991, $113,4583-4588$.

(19) Turner, S. R.; Vait, B. I.; Mourey, T. H. Macromolecules 1993, 26 4617-4623.

MA9902504 